\title{
Construction and Application of Interactive Translation Mobile Teaching Mode Based on WeChat
}

\author{
Huiqin Ning \\ Nanyang Institute of Technology, Nanyang, Henan, 473000
}

Keywords: WeChat, Teaching Mode, Interactive Translation

\begin{abstract}
In the age of the Internet, the traditional teaching mode is difficult to meet the needs of education. The teaching mode of WeChat's interactive translation and mobile has been put forward constantly. Through the application of this mode, the classroom teaching can be more relaxing and effective, so that students can learn more actively. From WeChat mobile learning support function and its model, its support for functional characteristics and learning patterns were introduced briefly. And then the paper starts to discuss the mobile teaching advantages on the WeChat platform, in order to make readers know well the necessity of this model in current education, and finally, it analyzes the construction and application of WeChat's interactive translation and mobile teaching mode, and makes an in-depth analysis from two aspects: theoretical foundation building and interactive application in translation teaching, therefore, readers will have a deeper understanding on the interactive translation teaching model.
\end{abstract}

\section{Introduction}

With the continuous development of the mobile Internet and its wireless communication technology, users can use the real-time communication software of the mobile terminal such as WeChat to communicate and interact with friends anytime, anywhere in the form of text, voice, video chat and the like. According to WeChat application population, we can see that college students are more interested in it, which also laid the WeChat mobile teaching position. Therefore, under the guidance of constructivism theory, how to construct a mobile teaching model of WeChat interactive translation and how to make the WeChat supportive function fully used in translation teaching is of great significance.

\section{Mobile Learning and WeChat Mobile Learning Support}

Mobile Learning began with the Wireless Andrew project at Carnegie Mellon University in the United States in 1994. At the 40th anniversary of Shanghai TV University in 2000, Dr. Keegan gave an academic report entitled "From Distance Learning to E-Learning to Mobile Learning" and the concept of mobile learning was introduced into China. As a new learning method, there is not a unified definition of mobile learning. Many scholars (Quinn, 2000; Dye et al., 2001; Hummel et al., 2003; Huang Dequn, 2005; Yu Shengquan, 2007) There is a slight difference in the definition of mobile learning but there is one thing in common: emphasis is placed on learning anytime, anywhere. As Dye et al. (2001) argue, "Mobile learning is a type of learning that can take place anywhere, anytime, with the help of a mobile device. Mobile computing devices used in mobile learning must be able to efficiently present content and provide teachers and / Two-way communication between learners. "By this definition we can see that mobile learning can also be called mobile teaching [1]. This article uses "mobile teaching" is intended to highlight the importance of teacher-student interaction in the learning process. The current mobile learning model are: (1) mobile-based mobile SMS learning; (2) multimedia-based mobile mail learning; (3) mobile learning based on mobile learning software; (4) mobile learning based on online browsing; (5) mobile learning based on real-time interactive software. Among them, there are shortcomings in the first four modes, such as poor instantaneous interaction, relatively simple forms or relatively 
high interactive costs. And the fifth kind, because the real-time interactive software has a lot of advantages such as powerful interaction, low cost, simple operation, wide usage and so on, it is ideal for mobile teaching. However, its interaction depends largely on the choice of interactive software. At present, the instant social software with large user groups includes WeChat, mobile QQ, Weibo and so on. In view of the more powerful mobile learning support function of WeChat and the high usage rate among college students, this study attempts to construct a micro-channel based interaction Translation of mobile teaching model to aid translation teaching [2].

WeChat software can be used for mobile learning main functions are: (1) Chat: Users can send text, pictures, voice and video and other media forms of information with friends private chat, group chat, support for two-video communication and real-time multi-person Speaking; (2) circle of friends to share: the function is equivalent to the blog, users can publish text in the circle of friends, pictures, web site links and other information to share with friends, friends can comment, forwarding or collection, etc. (3) plug-in: WeChat built- Plug-ins (Table 1), the user can choose to open on demand, plug-in features make the interaction more three-dimensional, diverse and efficient. It can be said that WeChat integrates a variety of functions such as SMS, mobile phone call, email, microblogging and forums to form a simple and efficient multi-modal and integrated mobile interactive platform. Various interactive modes make the interaction become more flexible and unobstructed. WeChat is convenient and has a good user experience. It is currently the most mobile-friendly mobile communication software and enjoys high usage and adhesion among college students. In addition, compared with Weibo, mobile QQ and other instant messaging software, WeChat pay more attention to protecting the privacy of users, joining the WeChat group requires a friend's invitation; friends circle, only each other as friends to browse, comment, forward the other party's information, to avoid the external non-related comments on the teaching of interference. These advantages of WeChat provide platform support and technical support for the construction of interactive translation mobile teaching mode.

\section{Construction and Application of Interactive Translation Mobile Teaching Model on the WeChat Platform}

The main theoretical basis for the construction of interactive translation and mobile teaching mode in WeChat platform is that "as the main body of cognitive activity, students can take the initiative to receive instillation of knowledge without being stimulated by external stimuli, rather than being passive." The Learner's Learning and Learning Resources, Teachers, media, etc. are all interacting with each other. In addition, more or should pay attention to and emphasize the subjective role of students, students as the core, so that students consciously mobilize to learn subjective initiative and enthusiasm, and in the student's entire study, teachers should play a guiding, organizing, helping This is the view put forward by Kafai \& Resnik [3]. Therefore, in the process of interactive translation teaching, teachers and students pay attention to the consultation and cooperation between students and students, and attach importance to the students to use the learning environment to construct self-translation skills, and as a student learning mentor, teachers should The design of a variety of teaching activities in line with the personality development of students, but also to better motivate students and their classmates, teachers exchange of resources between learning.

Based on the support function and its model of WeChat Mobile Learning described above, we can see that teaching in interactive translation can not be confined to classroom teaching of knowledge, but also to make full use of WeChat platform to broaden teaching channels. As in the classroom teachers should do a good job in guiding the students to play a subjective initiative to actively read the text to be translated, and to strengthen the teacher-student contact. In class, we should use the WeChat platform or create micro-channel communication group to achieve the interaction under the class. Teachers can also organize students to create micro-channel translation group, and will be conducive to improving students' translation ability of the information, literature and other uploaded to the WeChat platform, to achieve resource sharing. Or teachers use the 
WeChat group to collect the collected and filtered translation materials to the exchange group, and teachers and students can also receive the relevant translation problems and students to discuss and solve the problem together effectively to shorten the division Students, the distance between students. In short, through the understanding of WeChat platform and its application, WeChat interactive can effectively promote the students' translation level, but also in the actual remote online education is mainly by students and learning resources, students and students three kinds of interaction [4]. In the interactive construction of a new model of translation teaching, the three interactive to better integrate and throughout the process of translation teaching, in order to be able to deeper understanding of the specific application of interactive translation of mobile teaching mode, will also be from the following Several aspects to discuss:

First, resource sharing and interaction. In this mode, sharing information resources more quickly and easily. Students and teachers can share the obtained translation-related information resources in the form of a network or a book, and send them to WeChat circle of friends or resource sharing groups for sharing and sharing with others. As a translation teaching resource constructed by teachers and students, information resources group can also be viewed, studied and exchanged between teachers and students at anytime and anywhere. This makes interactive interaction between teachers, students, students, teachers and students and learning resources sufficient Reflected. Second, translation practice interaction. Practice is a necessary way to improve translation skills. In the new model, after the students complete the translation according to the teacher's requirements, the students can send the translations in the form of texts or pictures to the assignment exchange group so that the teachers can further understand how to translate the students' Also be able to communicate and comment on each other. For students who cooperate in translation, students should send translations that have been independently translated in advance to the cooperation and exchange group for discussion, and eventually produce a translation of the group, which will then be sent by the representatives of each group to the assignment exchange group. Finally, teachers will be able to make comments and explanations based on the translations of the various groups. In this way, students can find problems, innovate thinking, think and question in such a diversified interactive translation teaching, and ultimately regard translation practice as a learning process that learns and explores autonomously, and students and students make progress together. Students, The ability to translate and self-thinking can also be relatively improved. Third, students feedback interaction. Feedback from students 'learning and teaching reflects not only the effect of teaching, but more importantly, through the feedback of learning and teaching, teachers can timely adjust the teaching methods and methods so as to optimize the teaching and promote the students' translation level. In this new model, the translation teaching feedback channel is also gradually widened, and learning feedback has become more convenient and rapid. Teachers can chat with students directly on the WeChat platform or communicate directly with the students to understand their teaching and learning opinions, and actively listen to the feedback of students, communicate more with students to design a better translation Teaching plan [5]. Fourth, the translation review interaction. In translation teaching, reviewing students' translation assignments and giving feedback is not only to record the students' daily scores, but more importantly to understand students' translations through assignments and to make students gain their own shortcomings from the comments. Under the new model, teachers can not only evaluate students' translations without any limitation of time and place, but also timely feedback comments on translations by using voice messages. Students can also communicate online during the review process. In addition, teachers can actively organize students to participate in translation reviews, allowing students to set up homework exchange groups, discussion groups and other peer reviews, group reviews. In this way, teacher review can reduce the burden as well as effectively promote common learning among students.

\section{Conclusions}

The interactive translation mobile teaching mode based on the WeChat platform uses mobile communication devices to interact anytime, anywhere and in various forms to solve the problem that the interaction in the traditional translation teaching mode is limited by time and space. This 
not only enables students' the active interaction among others can be tempered and improved, and it is also conducive to cultivating students' cooperation and innovative ability so as to effectively improve the effectiveness of translation teaching. Of course, there are still some imperfections in this new teaching mode. For example, students with poor self-control may easily turn their attention to something other than online games when learning from a mobile device. Teachers need to spend a lot of time outside of class and energy preparation and construction of curriculum resources, resulting in instructors difficult to adhere to. Of course, there is bound to be room for improvement in a new type of teaching model, which needs to be continuously explored and gradually improved in practice.

\section{References}

[1] Zhu Xuewei, Zhu Yu, Xu Xiaoli. Research and Design of Mobile Learning Platform Supported by Wechat [J]. China Distance Education. 2014 (04):12-13.

[2] Wang Ping. WeChat Mobile Learning Support Function and Design Principles [J]. Distance Education Magazine. 2013 (06):71-74.

[3] Cao Yingchun. Discussion on the Teaching Mode of Three-dimensional Interactive Modular Translation [J]. Journal of Donghua University of Technology (Social Science Edition). 2013 (01):31-38.

[4] Bai Hao, Hao Jingjing. WeChat public platform in the field of university education in the application of [J]. China Education Information. 2013 (04):87-95.

[5] Yang Lifang. The application of mobile learning in college English vocabulary learning [J]. Foreign language teaching. 2012 (04):102-110. 